\title{
PENERAPAN ELEKTRO PNEUMATIK PADA ALAT BANTU SEKUR KLEP MENGGUNAKAN GERAK LINIER SILINDER PNEUMATIK YANG DIUBAH MENJADI GERAK ROTASI
}

\author{
Suyadi, Agus Pramono, Wahyu Djalmono Putro, Eko Armanto \\ ${ }^{1)}$ Jurusan Teknik Mesin Politeknik Negeri Semarang \\ JL. Prof. Sudharto, SH Tembalang Semarang, 50275 \\ Email : suyadimt@yahoo.com
}

\begin{abstract}
Abstrak
Tujuan penelitian ini adalah merancang dan membuat alat bantu yang dapat digunakan pada proses mensekur klep pada blok mesin sepeda motor dengan menggunakan sistem pneumatik sebagai penjepit blok mesin dan sebagai penggerak rack dan pinion sebagai fungsi pengganti gerakan tangan manusia sehingga dapat diatur dan dioperasikan secara semi otomatis dengan elektropneumatik supaya bisa menghemat waktu penyekuran, karena proses penyekuran secara manual yang biasa dilakukan dapat memakan waktu yang lama sekitar 90 sampai 120 menit. Dengan menggunakan alat bantu sekur klep waktu sekur klep lebih pendek menjadi 10 sampai 17,5 menit sebagai hasil penenelitian ini. Adapun metode penelitian ini antara lain mendesain, pembuatan komponen, perakitan hingga sampai proses pengujian dan pengambilan data. Hasil rancang bangun alat bantu sekur klep dengan sistem elektro pneumatik juga dapat digunakan untuk proses pembelajaran mahasiswa teknik mesin di laboratorium kontrol Fluida.
\end{abstract}

Kata Kunci : "sekur"," klep", dan "elektro pneumatik"

\section{Pendahuluan}

Penggunaan kendaraan bermotor sebagai alat transportasi semakin meningkat demikian pula banyak kita jumpai berbagai macam kerusakan yang ada pada mesin dan untuk sepeda motor yang paling sering adalah kebocoran klep pada cylinder head yaitu dimana timbul tumpukan kerak yang melekat pada seating klep sehingga mengganggu proses kompresi dan menurunkan kinerja mesin. Gejala-gejala yang timbul adalah kinerja mesin yang berkurang karena kompresi kurang maksimal, mesin akan cepat mati karena kinerja mesin tidak stabil, boros bahan bakar. Penyebab kerak salah satunya disebabakan karena oli masuk ke ruang pembakaran, untuk mengatasi hal ini diperlukan perbaikan untuk mengatasi kebocoran klep tersebut yaitu penyekuran klep (valve lapping).

Berdasarkan observasi peneliti di Bengkel di sekitar Banyumanik dan Pucang Gading Semarang masih ada cara manual (tradisional) dalam melakukan, yaitu dengan cara memutar dengan tangan gagang klep ke kanan ke kiri dan ke atas ke bawah, dengan menggunakan kedua tangan maka waktu yang dibutuhkan penyekuran jadi lama dan tidak efisien tetapi walaupun demikian tidak semua teknisi bengkel bisa melakukan penyekuran seperti itu.

Untuk mengatasi proses manual dalam pengerjaan penyekuran klep agar klep tidak bocor dan terpasang rapat antara klep dengan dudukannya dengan baik diperlukan alat bantu sekur klep dengan menggunakan aplikasi elektro-pneumatik dengan cara mengubah gerak linier silinder menjadi gerak rotasi, alat bantu sekur klep ini diharapkan mampu mengatasi kesulitan dalam mengatur gerakan penyekuran manual dengan tangan karena gerakan tangan ini tidak stabil sehingga hasil penyekuran klep tidak teliti yang mengakibatkan permukaan klep tidak rata sehingga masih terjadi kebocoran. Pembuatan alat bantu sekur klep dengan aplikasi elektro-pneumatik hasil penelitian ini bisa diterapkan di bengkel-bengkel sekur klep, selain itu juga bisa digunakan sebagai alat pembelalajaran praktek pneumatik mahasiswa teknik mesin sehingga mahasiswa akan lebih mudah dalam memahami aplikasi elektro-pneumatik dalam melakukan prakteknya.. 


\section{Metode Penelitian}

Tahapan penelitian dan semua rangkaian kegiatan akan kami lakukan di Laboratorium Teknik Mesin Politeknik Negeri Semarang. Adapun tahapan penelitian ini sebagai berikut :

\section{Studi Literatur}

Pada studi ini dimaksudkan untuk menggali permasalahan aplikasi elektro-pneumatik yang relean dengan teknik mesin berdasarkan teori dan beberapa referensi yang ada.

\section{Observasi}

Observsi di lapangan dalam upaya untuk mengidentifikasi permasalahan bengkel sekur klep yang ada di Semarang.

\section{Merancang Alat Bantu Sekur Klep}

Berdasarkan hasil identifikasi permasalah proses sekur klep tradisional/manual banyak ditemukan permasalahan penyekuran tidak teliti karena gerakan tangan saat penyekuran tidak konsisten maka perlu merancang alat bantu sekur klep sistem elektro-pneumatik

Pembuatan Alat Bantu Sekur Klep sistem Elektro-Pneumatik

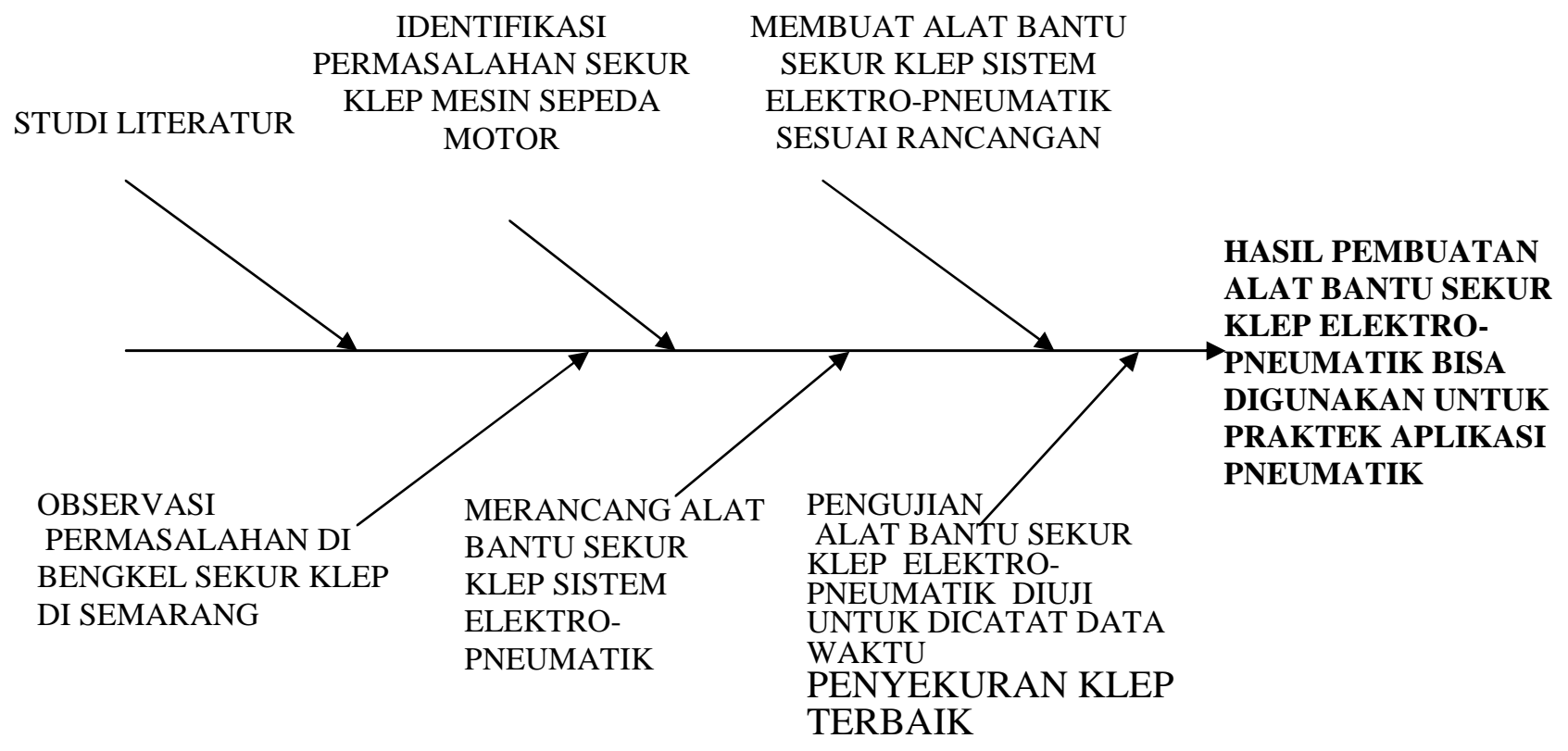

Gambar 1. Diagram Fishbone Penelitian
Pembuatan alat bantu sekur klep berdasarkan gambar rancangan sebelumnya, tahap pertama membuat kerangka meja tempat dudukan elektro-pneumatik dan tahap kedua merakit komponen-komponen elektropneumatik beserta aktuator silindernya.

\section{Pengujian Hasil Pembuatan Alat Bantu Sekur Klep}

Pengujian alat merupakan tolok ukur keberhasilan penelitian, karena tanpa pengujian niscaya penelitiannya belum mencapai tujuannya. Adapun pengujian dilakukan untuk mengetahui berfungsi tidaknya alat bantu sekur bekerja dengan baik, pengujian ini dilakukan dengan menyekur tiga sampel klep pada blok mesin sepeda motor, pengujian dengan mencatat data lamanya waktu penyekuran yang terbaik baik pada klep hisap (intake) dan klep buang (exhaust), tolok ukur pensekuran terbaik adalah kalau klep dipasangkan pada dudukannya tidak terjadi bocor (rapat) dengan cara meneteskan cairan bahan bakar bensin. 


\section{Hasil Dan Pembahasan}

\subsection{Hasil Rancang Bangun Penelitian}

Pada penelitian ini berupa pembuatan alat bantu sekur klep dengan penggerak silinder pneumatik diubah mnjadi gerak rotasi bolak balik.

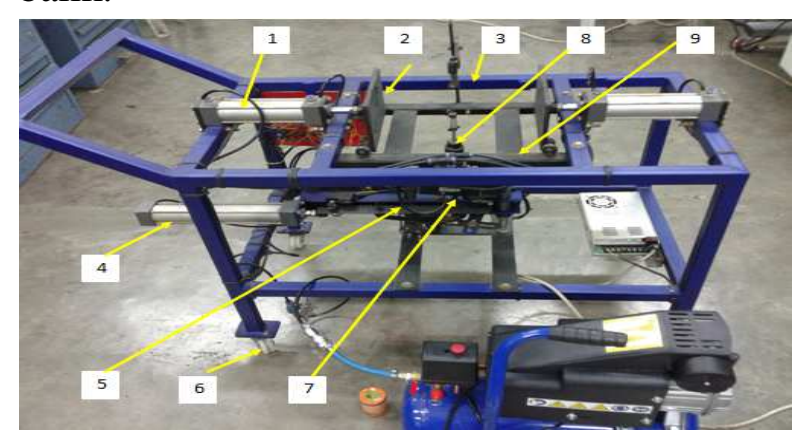

Gambar 2. Alat bantu sekur klep

Keterangan :

1. Double Acting Cylinder A dan B (untuk mencekam slilinder head )

2. Spons peredam

3. Kerangka

4. Double Acting Cylinder C (untuk menggerakkan Rack and Pinion)

5. Rack and Pinion

6. Roda

7. Double Acting Cylinder D (untuk menaik turunkan klep)

8. Pencekam Klep

9. Landasan Peluncur

\section{- Langkah Kerja Sebelum Pengujian Alat}

- Hubungkan selang pneumatik dari 2 buah double acting cylinder bagian atas dengan sambungan $\mathrm{T}$, hubungkan ke sebuah katup 5/2 solenoid ganda sebelum dihubungkan kasih terlebih dahulu katup pengatur aliran. Hubungkan selang pada $5 / 2$ solenoid ganda dengan kompresor, hubungkan kable 5/2 solenoid ganda dengan saklar.

- Hubungkan selang pneumatik pada 2 buah double acting cylinder bagian bawah dengan Katup pengatur aliran, hubungkan dengan 2 buah katup 5/2 solenoid ganda . hubungkan selang pada $5 / 2$ solenoid ganda dengan kompresor , hubungkan kabel 5/2 solenoid ganda dengan saklar
- Hubungkan kable yang ada di limit switch dengan saklar

- Hubungkan kabel-kabel ke posisi/tempat yang telah ditentukan, hubungkan ralay dan saklar dengan menggunakan kabel

- Hubungkan kable (+) dan (-) yang ada di saklar dengan power supply

\subsection{Hasil Pengujian}

Pengujian dilakukan dengan melakukan keberhasilan pengujian fungsi alat dan pengujian pengambilan data waktu pensekuran yang baik sekali dengan parameter keberhasilan tidak ada kebocoran pada lobang masukan (intake) dan pembuangan (exhaust)

Tabel 1. Dudukan Klep Terhadap Klep pada Blok Mesin Sepeda Motor 1

\begin{tabular}{|l|l|l|l|l|}
\hline Jenis Klep & Pengujian & $\begin{array}{c}\text { Waktu } \\
\text { Penyekuran }\end{array}$ & $\begin{array}{c}\text { Hasil } \\
\text { Penyekuran }\end{array}$ & $\begin{array}{c}\text { Kualitas } \\
\text { Hasil } \\
\text { Penyekuran }\end{array}$ \\
\hline \multirow{3}{*}{$\begin{array}{l}\text { Klep } \\
\text { Intake }\end{array}$} & 1 & 2,5 menit & Masih bocor & Belum baik \\
\cline { 2 - 5 } & 2 & 5 menit & Masih bocor & Belum baik \\
\cline { 2 - 5 } & 3 & 7,5 menit & Masih bocor & Belum baik \\
\cline { 2 - 5 } & 4 & 10 menit & Masih Bocor & Belum baik \\
\cline { 2 - 5 } & 5 & 12,5 menit & Merembes & Baik \\
\cline { 2 - 5 } & 6 & 15 menit & Rapat & Baik sekali \\
\cline { 2 - 5 } Exhaust & 7 & 17,5 menit & Rapat & Baik sekali \\
\cline { 2 - 5 } & 8 & 20 menit & Rapat & Baik sekali \\
\cline { 2 - 5 } & 1 & 2,5 menit & Masih bocor & Belum baik \\
\cline { 2 - 5 } & 2 & 5 menit & Masih bocor & Belum baik \\
\cline { 2 - 5 } & 4 & 7,5 menit & Masih bocor & Belum baik \\
\cline { 2 - 5 } & 5 & 10 menit & Masih Bocor & Belum baik \\
\cline { 2 - 5 } & 6 & 12,5 menit & Masih bocor & Belum baik \\
\cline { 2 - 5 } & 7 & 15 menit & Merembes & Baik \\
\cline { 2 - 5 } & 8 & 17,5 menit & Rapat & Baik sekali \\
\hline
\end{tabular}

Tabel 2.DudukanKlep Terhadap Klep pada Blok Mesin SepedaMotor 2

\begin{tabular}{|l|l|l|l|l|}
\hline $\begin{array}{c}\text { Jenis } \\
\text { Klep }\end{array}$ & Pengujian & $\begin{array}{c}\text { Waktu } \\
\text { Penyekuran }\end{array}$ & $\begin{array}{c}\text { Hasil } \\
\text { Penyekuran }\end{array}$ & $\begin{array}{c}\text { Kualitas } \\
\text { Hasil } \\
\text { Penyekuran }\end{array}$ \\
\hline $\begin{array}{l}\text { Klep } \\
\text { Intake }\end{array}$ & 1 & 2,5 menit & Masih bocor & Belum baik \\
\cline { 2 - 5 } & 2 & 5 menit & Masih bocor & Belum baik \\
\cline { 2 - 5 } & 3 & 7,5 menit & Masih bocor & Belum baik \\
\cline { 2 - 5 } & 4 & 10 menit & Masih Bocor & Belum baik \\
\cline { 2 - 5 } & 5 & 12,5 menit & Merembes & Baik \\
\cline { 2 - 5 } & 6 & 15 menit & Rapat & Baik sekali \\
\cline { 2 - 5 } & 7 & 17,5 menit & Rapat & Baik sekali \\
\cline { 2 - 5 } Elep & 8 & 20 menit & Rapat & Baik sekali \\
\cline { 2 - 5 } & 1 & 2,5 menit & Masih bocor & Belum baik \\
\cline { 2 - 5 } & 2 & 5 menit & Masih bocor & Belum baik \\
\cline { 2 - 5 } & 3 & 7,5 menit & Masih bocor & Belum baik \\
\cline { 2 - 5 } & 5 & 10 menit & Masih Bocor & Belum baik \\
\cline { 2 - 5 } & 6 & 12,5 menit & Masih bocor & Belum baik \\
\cline { 2 - 5 } & 7 & 15 menit & Merembes & Baik \\
\cline { 2 - 5 } & 8 & 17,5 menit & Rapat & Baik sekali \\
\hline \multirow{4}{*}{ Ext } & 20 menit & Rapat & Baik sekali \\
\hline
\end{tabular}


Tabel 3.DudukanKlep Terhadap Klep pada Blok Mesin SepedaMotor 3

\begin{tabular}{|c|c|c|c|c|}
\hline $\begin{array}{l}\text { Jenis } \\
\text { Klep }\end{array}$ & $\begin{array}{c}\text { Pengujia } \\
\mathbf{n}\end{array}$ & $\begin{array}{c}\text { Waktu } \\
\text { Penyekura } \\
\text { n }\end{array}$ & $\begin{array}{c}\text { Hasil } \\
\text { Penyekura } \\
\mathbf{n}\end{array}$ & $\begin{array}{c}\text { Kualitas } \\
\text { Hasil } \\
\text { Penyekura } \\
\text { n }\end{array}$ \\
\hline \multirow{8}{*}{$\begin{array}{l}\text { Klep } \\
\text { Intake }\end{array}$} & 1 & 2,5 menit & Masih bocor & Belum baik \\
\hline & 2 & 5 menit & Masih bocor & Belum baik \\
\hline & 3 & 7,5 menit & Merembes & Baik \\
\hline & 4 & 10 menit & Rapat & Baik sekali \\
\hline & 5 & 12,5 menit & Rapat & Baik sekali \\
\hline & 6 & 15 menit & Rapat & Baik sekali \\
\hline & 7 & 17,5 menit & Rapat & Baik sekali \\
\hline & 8 & 20 menit & Rapat & Baik sekali \\
\hline \multirow{8}{*}{$\begin{array}{l}\text { Klep } \\
\text { Exhaus } \\
\text { t }\end{array}$} & 1 & 2,5 menit & Masih bocor & Belum baik \\
\hline & 2 & 5 menit & Masih bocor & Belum baik \\
\hline & 3 & 7,5 menit & Masih bocor & Belum baik \\
\hline & 4 & 10 menit & Merembes & Baik \\
\hline & 5 & 12,5 menit & Rapat & Baik sekali \\
\hline & 6 & 15 menit & Rapat & Baik sekali \\
\hline & 7 & 17,5 menit & Rapat & Baik sekali \\
\hline & 8 & 20 menit & Rapat & Baik sekali \\
\hline
\end{tabular}

\subsection{Pembahasan Hasil Penelitian.}

Berdasarkan data hasil pengujian pensekuran antara klep dan dudukan klep pada blok mesin sepeda motor1, 2, dan 3 (ada 3 sampel blok mesin sepeda motor yang disekur) masing-masing blok mesin terdapat satu klep hisap (intake) dan satu klep buang (exhaust) telah berhasil disekur dengan baik sekali dimana ditunjukkan dengan uji kebocoran, bila katup dan dudukan katup rapat menunjukkan pensekuran baik sekali, bila merembes menunjukkan pensekuran baik dan bilamasih bocor menunjukkan pensekura kurang baik.



Gambar 3. Hubungan waktu pensekuran terhadap kualitas hasil sekur blok mesin 1
Keterangan :

- Kualitas pensekuran 1 adalah kurang baik

- Kualitas pensekuran 2 adalah baik

- Kualitas pensekuran 1 adalah baik sekali

- Series 1 adalah klep hisap (intake)

- Series 2 adalah klep buang (exhaust)

Berdasarkan data tabel 1 dan gambar 3 hasil penelitian pensekuran dudukan klep dan klepnya pada blok msein sepeda motor 1 menunjukan untuk klep hisap memerlukan waktu pensekuran 15 menit untuk mendapatkan kualitas baik sekali dan untuk pensekuran klep buang agar baik sekali memerlukan waktu 17,5 menit

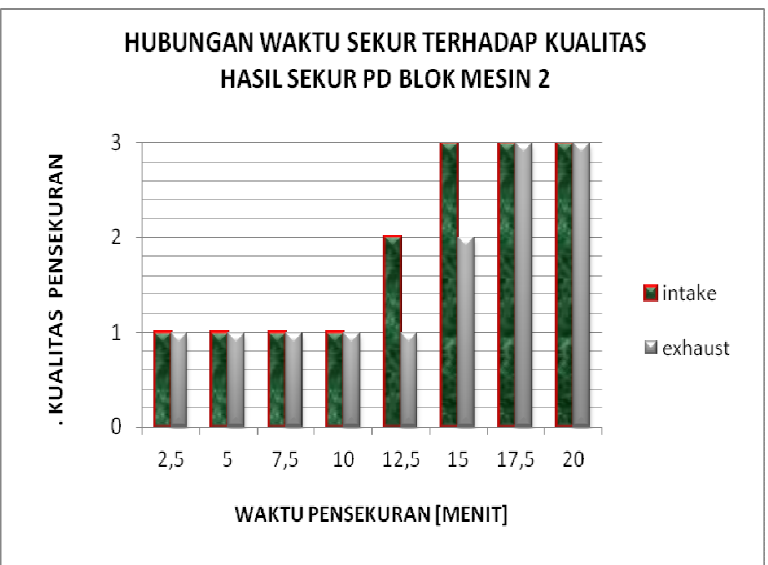

Gambar 4. Hubungan waktu pensekuran terhadap kualitas hasil sekur blok mesin 2

Keterangan :

- Kualitas pensekuran 1 adalah kurang baik

- Kualitas pensekuran 2 adalah baik

- Kualitas pensekuran 1 adalah baik sekali

- Series 1 adalah klep hisap (intake)

- Series 2 adalah klep buang (exhaust)

Berdasarkan data tabel 2 dan gambar 4 hasil penelitian pensekuran dudukan klep dan klepnya pada blok msein sepeda motor 1 menunjukan untuk klep hisap memerlukan waktu pensekuran 15 menit untuk mendapatkan kualitas baik sekali dan untuk pensekuran klep buang agar baik sekali memerlukan waktu 17,5 menit (kebetulan hasil pengujian sama dengan pengujian pensekuran pada blok mesin sepeda motor 1 . 


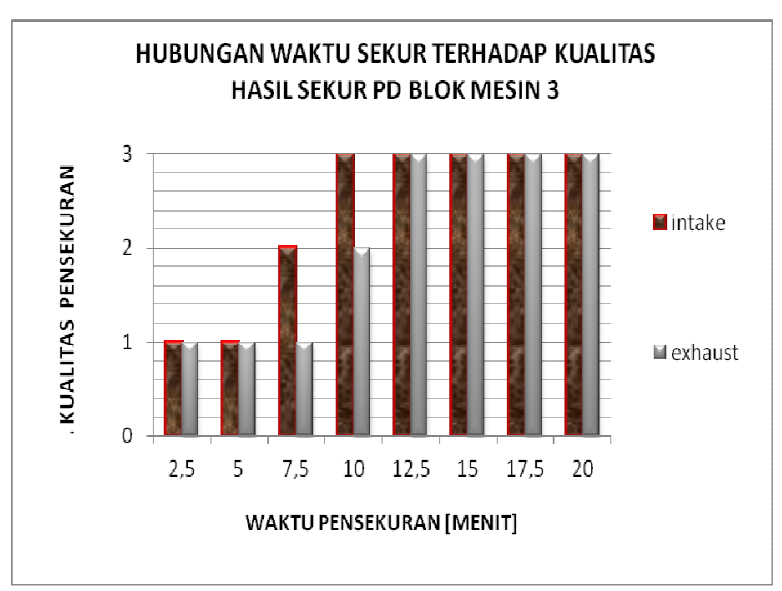

\section{Gambar 5. Hubungan waktu pensekuran terhadap kualitas hasil sekur blok mesin 3}

Keterangan :

- Kualitas pensekuran 1 adalah kurang baik

- Kualitas pensekuran 2 adalah baik

- Kualitas pensekuran 1 adalah baik sekali

- Series 1 adalah klep hisap (intake)

- Series 2 adalah klep buang (exhaust)

Berdasarkan data tabel 3 dan gambar 5 hasil penelitian pensekuran dudukan klep dan klepnya pada blok msein sepeda motor 1 menunjukan untuk klep hisap memerlukan waktu pensekuran 10 menit untuk mendapatkan kualitas baik sekali dan untuk pensekuran klep buang agar baik sekali memerlukan waktu 12,5 menit (hasil pengujian tidak sama dengan pengujian pensekuran pada blok mesin sepeda motor 1 atau 2)

Dari keseluruhan 3 sampel uji blok mesin sepeda motor 1, 2, dan 3 dapat disimpulkan bahwa pensekuran minimal memerlukan waktu 10 menit untuk klep hisap (intake)dan perlu waktu pensekuran 12,5 menit untuk klep buang (exhaust) yaitu pada pengujian pensekuran blok mesin sepeda motor 3 . Adapun untuk pengujian pensekuran blok mesin sepeda motor 1 dan 2 mengahasilan pensekuran yang baik sekali perlu waktu 15 menit untuk dudukan klep hisap (intake) dan untuk dudukan katup buang (exhaust) memerlukan waktu pensekuran 17,5 menit.

Perbedaan waktu pensekuran yang dibutuhkan antara ketiga sampel uji satu dengan yang lainnya disebabkan oleh kondisi awal dudukan klep dan klepnya masingmasing berbeda bisa disebabkan oleh tahun pembutan mesin masing-masing sampel uji berbeda, perbedaan yang lain juga karena cara perawatannya, cara menggunakan sepeda motornya dan juga karena perbedaan penggunaan bahan bakarnya. Sedangkan untuk waktu pensekuran pada dudukan klep dan klep pada klep exhaust lebih lama dari klep intake dikarenakan pada klep buat dilewati gas buang dari pembakaran yang bisa mempercepat menumpuknya kotoran hasil pembakaran.

\section{Kesimpulan}

Luaran peenelitian ini berupa alat bantu sekur klep menggunakan gerak linier pneumatik yang diubah menjadi gerak rotasi dan dari hasil pengujian dapat disimpulkan sbb :

1. Pengujian kualitas pensekuran yang baik sekali adalah pada dudukan klep dan klepnya pada blok mesin sepeda motor 3 dengan waktu pensekuran 10 menit untuk klep hisap.(intake) dan 12,5 menit untuk klep buang (exhaust)

2. Dari tiga sampel uji hanya sampel uji 1 dan 2 menunjukkan hasil yang sama yaitu waktu pensekuran 15 menit untuk klep hisap.(intake) dan 17,5 menit untuk klep buang (exhaust).

3. Waktu pensekuran pada klep hisap lebih cepat daripada klep buang karena dilalui gas buang yang menyebabkan lebih cepat menumpuknya sisa pembakaran.

4. Penyebab perbedaan waktu pensekuran antara masing-masing sampel uji karena sampel uji pada kondisi awalnya tidak diketahui seperti umur mesin sepeda motor sudah berapa lama dipakai. 


\section{Daftar Pustaka}

- FESTO, 1991, Electro Pneumatics.

- Histand, Michael B, 1999, Mechatronics, McGraw Hill, Singapore.

- Khurmi, R.S \& Gupta, J.K. 2005. A Text Book of Machine Design. Eurasia Publishing House (Pvt) Ltd.

- Meixner. H \& Kobler. 1978. Introduction To Pneumatics. Festo Ditactic: Germany.

- Meriam, JL, 1993, Mekanika Teknik Dinamika, Erlangga, Jakarta.

- Muljowidodo, 1996, Mekatronika, HEDS, ITB.
- Ogata, Katsuhiko (1996), Teknik Kontrol Automatik, Erlangga, Jakarta.

- Parr, Andrew.2003.Hidrolik dan Pneumatika.Pedoman Bagi Tekhnisi dan Insinyur.PT. Gelora Aksara Pratama(Erlangga):Jakarta

- Sularso \& Kiyokatsu Suga. 1978. Dasar Perancangan dan Pemilihan Elemen Mesin. PT. Pradnya Paramita: Jakarta.

- http://www.ivteh.ru/in/_notes/katfit.pdf diunduh tanggal 1 Agustus 2015 